\title{
Descentralização e regionalização da política de saúde: abordagem histórico-comparada entre o Brasil e a Espanha
}

\author{
Decentralization and regionalization of health policy: \\ a historical-comparative approach between Brazil and Spain
}

Adelyne Maria Mendes Pereira ${ }^{1}$

Luciana Dias de Lima ${ }^{1}$

Cristiani Vieira Machado ${ }^{1}$

${ }^{1}$ Departamento de Administração e Planejamento em Saúde, Escola Nacional de Saúde Pública Sergio Arouca, Fiocruz. R. Leopoldo Bulhões 1480, Manguinhos. 21041-210 Rio de Janeiro RJ Brasil. adelyne.pereira@ ensp.fiocruz.br

\begin{abstract}
This article discusses the processes of decentralization and regionalization of health policy in Brazil and Spain between 1980 and 2015. The study was developed with contributions of the historical institutionalism and of the historical-comparative method, by means of three dimensions of analysis: State context; trajectory and institutionality of the decentralization and regionalization of health; and constraints. The study showed that, in both countries, the more general context of redemocratization and decentralization of the State conditioned the reforms of health systems and their political-administrative organization. In addition, historical, institutional and political factors have had a specific impact in each case, influencing the regional organization of services, the balance of power and the division of responsibilities between the governmental spheres in the management, financing and coordination of health policy. The study suggests that the way these factors interrelated over time is important for understanding the decentralization and regionalization of health systems in different contexts.
\end{abstract}

Key words Decentralization of health, Regionalization of health, Health systems, Comparative health policy, Brazil and Spain
Resumo Este artigo aborda os processos de descentralização e regionalização da política de saúde no Brasil e na Espanha entre 1980 e 2015. Valendo-se de contribuições do institucionalismo histórico e do método histórico-comparado, o estudo foi desenvolvido a partir de três dimensões de análise: contexto estatal; trajetória e institucionalidade da descentralização e regionalização da saúde; e condicionantes. O estudo evidenciou que, em ambos os países, o contexto mais geral de redemocratização e descentralização do Estado condicionou as reformas dos sistemas de saúde e sua organização político-administrativa. Além disso, fatores históricos, institucionais e políticos repercutiram, de modo específico em cada caso, influenciando a organização regional dos serviços, o balanço de poder e a divisão de responsabilidades entre as esferas governamentais na gestão, financiamento e coordenação da política de saúde. $O$ estudo sugere que o modo como estes fatores se interrelacionaram no tempo importa para a compreensão da descentralização e regionalização dos sistemas de saúde em diferentes contextos.

Palavras-chave Descentralização da saúde, Regionalização da saúde, Sistemas de saúde, Política de saúde comparada, Brasil e Espanha 


\section{Introdução}

A partir dos anos 1970, a descentralização se disseminou como um princípio ordenador dos processos de reforma dos Estados nacionais na Europa e na América Latina. Tais processos levaram a mudanças na distribuição do poder do Estado no território e nas políticas públicas. Os objetivos e a direcionalidade da descentralização variaram, em cada contexto, em função da natureza da coalizão política de sustentação das reformas ${ }^{1}$. De forma geral, as reformas descentralizadoras buscaram promover a democratização e ampliar a eficiência, a efetividade e os mecanismos de accountability das políticas públicas ${ }^{2,3}$. Em diversos países, destaca-se seu imbricamento com a regionalização dos sistemas de saúde, por meio da criação e fortalecimento de autoridades sanitárias regionais dotadas de maior responsabilidade na gestão, financiamento e organização da rede de serviços ${ }^{4}$.

$\mathrm{Na}$ Espanha, a descentralização foi impulsionada por governos socialistas, no contexto de transição democrática dos anos 1970 e 1980, buscando responder a demandas regionais ${ }^{5}$. Houve mudanças nas estruturas centralizadas de poder que resultaram na conformação de um novo nível de governo: as Comunidades Autônomas (CCAA). No Brasil, a descentralização foi compreendida como um caminho de oposição ao autoritarismo do regime militar que, no bojo do movimento de redemocratização dos anos 1980, trouxe implicações para a organização do federalismo brasileiro. Os municípios foram instituídos como entes federativos autônomos, tendo ampliadas suas atribuições na gestão de políticas públicas e de recursos fiscais ${ }^{1,6}$. Brasil e Espanha compartilharam uma agenda política semelhante, pautada na descentralização do poder territorial e no restabelecimento da democracia ${ }^{7}$. Esse foi um dos motivos para a seleção desses países como casos desse estudo.

No Brasil e na Espanha, a redemocratização do Estado deu consequência à reforma dos sistemas de saúde. O Sistema Nacional de Saúde espanhol (SNS) e o Sistema Único de Saúde brasileiro (SUS) representaram a conformação de modelos universais, com princípios e diretrizes semelhantes previstas em seus marcos legais. Contudo, as características dos processos de descentralização e regionalização da saúde nos dois casos mostraram-se diferentes. Essa é outra razão para a seleção desses casos, cuja justificativa se baseia no potencial da análise comparada dos fatores que podem condicionar suas similitudes e diferenças, tendo em vista o objeto deste estudo.
Na Espanha, descentralização e regionalização foram implementadas conjuntamente em um processo paulatino que se seguiu à articulação política das CCAA e à constituição de capacidades institucionais necessárias para que assumissem a responsabilidade pelo sistema de saúde em seu território, com autonomia de gestão e financiamento ${ }^{8}$. No Brasil, embora as diretrizes de descentralização e regionalização estivessem presentes no marco legal do sistema sanitário, sua implementação foi desarticulada na primeira década de implementação do SUS. Nesse período, a descentralização esteve direcionada em grande medida aos municípios, dando origem a um processo de municipalização descolado da constituição de regiões sanitárias. Somente nos anos 2000 houve uma reaproximação entre tais diretrizes no marco normativo do SUS, com o objetivo de promover a constituição de tais regiões ${ }^{9}$. Um dos desafios à regionalização do SUS é o desenvolvimento de instrumentos que fortaleçam a gestão compartilhada e as relações intergovernamentais em nível regional, a fim de promover a consolidação dessas regiões em termos de prestação de serviços, capacidade de gestão e de gasto.

Partindo do pressuposto de que o contexto mais geral de redemocratização e descentralização do Estado exerce influência sobre a reforma do sistema de saúde e sua organização político -administrativa, este artigo tem como objetivo analisar, em perspectiva comparada, a descentralização e a regionalização da política de saúde no Brasil e na Espanha de 1980 a 2015. Buscou-se responder a seguinte questão: que fatores históricos, políticos e institucionais favoreceram tais processos nesses países e como influenciaram a configuração recente dos sistemas de saúde em cada caso?

A justificativa para o artigo está centrada na importância de estudos comparados para compreensão dos contextos específicos em que as políticas de saúde são desenvolvidas em cada caso e a construção de explicações transversais a eles. A análise dos casos brasileiro e espanhol permite identificar fatores que condicionam os processos de descentralização e regionalização da saúde no contexto mais amplo de tranformação do Estado.

\section{Metodologia}

A pesquisa utilizou contribuições do referencial do institucionalismo histórico ${ }^{10,11}$, adotando como método a análise histórico-comparada ${ }^{12,13}$. Uma das principais características da análise his- 
tórico-comparada é voltar-se para experiências passadas que remetem a preocupações do presente, formulando questionamentos e hipóteses a respeito de um conjunto de casos que exibem similaridade suficiente para serem comparados. Entre as vantagens da análise histórico-comparada de poucos casos estão a proximidade (close- $a$ cquaintance) com a complexidade dos casos e a possibilidade de superação dos limites das análises internas ao caso (within-cases), deslocando-se para análises transversais a eles (across-cases) ${ }^{12}$.

O institucionalismo histórico valoriza a análise das dos atores, seus interesses e ações estratégicas no estudo das políticas públicas. Tal abordagem enfatiza a ideia do Estado como ator e, assim, o papel e a atuação das instituições e atores estatais. Além disso, outras duas ideias podem ser consideradas centrais: o reconhecimento de que a ação do Estado (e das suas instituições) é dotada de sentido, ou seja, influenciada pela relação de forças que se estabelece entre burocracias estatais, partidos políticos, grupos de interesses e outras estruturas presentes no interior das instituições, que podem tensionar uma política pública, acelerando-a ou a interrompendo; e de que a ação estatal é historicamente condicionada.

A partir desse referencial, foi construída uma matriz analítica em três dimensões - contexto estatal; trajetória e institucionalidade da descentralização e da regionalização da saúde; e con- dicionantes desses processos - cujas definições e componentes encontram-se especificados no Quadro 1. O desenho dessas dimensões é o resultado das mediações construídas entre o referencial e o objeto deste estudo, que se expressam na preocupação de articular a análise da descentralização e da regionalização da política de saúde com o contexto mais geral de descentralização do Estado brasileiro e espanhol (contexto estatal), valorizando seus contextos específicos e realizando uma análise transversal aos casos, de modo a elucidar aspectos formais (institucionalidade) e elementos da implementação (trajetória) desses processos ao longo do tempo, bem como seus condicionantes.

O período de estudo compreendeu os anos 1980 a 2015. Tal recorte temporal buscou abranger o período de reformas dos sistemas de saúde com ênfase na descentralização e regionalização nos dois casos, marcado inicialmente pela redemocratização e reforma do Estado (Espanha, final dos anos 1970 e anos 1980; Brasil, final dos anos 1980 e 1990) e que se estende aos anos 2000. A extensão do período de estudo foi importante para analisar a trajetória das diretrizes de descentralização e regionalização ao longo da implementação do SUS e do SNS.

As seguintes estratégias e técnicas de pesquisa foram utilizadas: revisão da literatura; análise documental (leis, atos normativos e documentos

Quadro 1. Matriz de análise para o estudo da descentralização e da regionalização da política de saúde.

\begin{tabular}{|l|l|l|}
\hline \multicolumn{1}{|c|}{ Dimensões de análise } & \multicolumn{1}{|c|}{ Definições } & \multicolumn{1}{c|}{ Componentes de Análise } \\
\hline $\begin{array}{l}\text { Contexto estatal } \\
\text { (Descentralização } \\
\text { do Estado) }\end{array}$ & $\begin{array}{l}\text { Contexto de redistribuição do } \\
\text { poder do Estado no território e } \\
\text { divisão de responsabilidades no } \\
\text { âmbito das políticas públicas. }\end{array}$ & $\begin{array}{l}\text { - Características da descentralização do Estado; } \\
\text { - Contexto político: ditadura x democracia, } \\
\text { orientação política dos governos e das reformas; } \\
\text { - Contexto econômico: crises econômicas e suas } \\
\text { repercussões; e evolução do gasto social público } \\
\text { total (\% do PIB). }\end{array}$ \\
\hline $\begin{array}{l}\text { Trajetória e } \\
\text { institucionalidade da } \\
\text { descentralização e da } \\
\text { regionalização da Saúde }\end{array}$ & $\begin{array}{l}\text { Processo de implementação } \\
\text { da descentralização e } \\
\text { regionalização da saúde, } \\
\text { marcado por regras formais } \\
\text { (marco legal e normativo) } \\
\text { que definem suas diretrizes } \\
\text { e conteúdos, bem como por } \\
\text { continuidades e rupturas. }\end{array}$ & $\begin{array}{l}\text { - Ideia/sentido (formal) acerca da } \\
\text { descentralização e da regionalização da saúde; } \\
\text { - Objetivos/desenho (formal) desses processos; } \\
\text { - Características da implementação dos processos } \\
\text { de descentralização e regionalização da saúde; } \\
\text { - Elementos de continuidade e mudança } \\
\text { presentes. }\end{array}$ \\
\hline Condicionantes & $\begin{array}{l}\text { Elementos do contexto } \\
\text { que exercem influência } \\
\text { sobre a descentralização e } \\
\text { regionalização da saúde, } \\
\text { considerando o papel das } \\
\text { instituições e dos atores. }\end{array}$ & $\begin{array}{l}\text { - Fatores políticos, institucionais e econômicos; } \\
\text { - Papel das instituições e dos atores; } \\
\text { - Estratégias de atuação das instituições e dos } \\
\text { atores. }\end{array}$ \\
\hline
\end{tabular}

Fonte: Elaboração própria. 
oficiais); consultas a especialistas; e análise de dados secundários disponíveis na base da Comissão Econômica para a América Latina e o Caribe (gasto social público total como percentual do PIB) e da Organização Mundial de Saúde (gasto total e público em saúde como percentual do PIB). O processamento e análise das informações foram orientados pela matriz, em suas dimensões e componentes.

\section{Resultados e discussão}

\section{Contexto estatal: descentralização do Estado}

O processo histórico de redemocratização da Espanha antecedeu o do Brasil, com a queda da ditadura franquista em 1975 e início do regime constitucional em 1978. No Brasil, a ditadura militar se estendeu até 1985 , com a aprovação da nova constituição em 1988. A aprovação de novos textos constitucionais foi um marco do retorno à democracia, que permitiu mudanças na distribuição do poder político-territorial nos dois países, com especificidades no que diz respeito aos sentidos e propósitos da descentralização.

No caso espanhol, tal processo guardou relação com a repressão à diversidade étnica, linguística e cultural das regiões ao longo da ditadura, procurando responder aos anseios nacionalistas e separatistas presentes. O resultado foi a criação de uma nova esfera de governo, as Comunidades Autônomas (CCAA), para a qual o processo de descentralização esteve dirigido. No Brasil, ainda que não tenha havido a criação de um novo nível de governo, a redemocratização trouxe mudanças para a divisão do poder territorial, com redistribuição de responsabilidades e funções administrativas, políticas e fiscais. Tal processo, influenciado pela simbiose entre democracia e descentralização, instituiu os municípios como entes federativos com o mesmo status jurídicoconstitucional da União e dos estados.

A análise comparada evidencia que, enquanto na Espanha a descentralização do Estado se propôs a gerar autonomia em regiões historicamente consolidadas, em um quadro de pressões e tensões separatistas; no Brasil, o propósito foi redistribuir poder e acomodar interesses estaduais e municipais. O balanço final em termos de equilíbrio de poder é diferente entre os casos, sugerindo, no primeiro, maior autonomia dos governos subnacionais e, no segundo, forte interdependência governamental.
Cabe destacar que há diferenças importantes entre o status dos governos subnacionais no Brasil e na Espanha. Na Espanha, a expressão governos subnacionais diz respeito às 17 CCAA que se constituíram no período pós-redemocratização, com ampla autonomia política, fazendo com que o país seja conhecido como o "Estado das Autonomias", um dos mais descentralizados da Europa ${ }^{5}$. No Brasil, os governos subnacionais se referem aos 26 estados e 5.570 municípios, com capacidades institucionais e políticas muito variadas, caracterizando uma federação assimétrica sob um modelo de federalismo simétrico, no qual a União possui um papel central. Por meio das obrigações constitucionais e da legislação nacional, a União limita o poder de decisão e formulação dos estados e municípios ${ }^{14}$, de maneira que, em cada política pública, seu poder aumenta à medida que põe em prática mecanismos de indução e regulação.

O contexto político e econômico também exerceu influência sobre a descentralização sanitária. A agenda de reforma neoliberal, que pressionou os sistemas de saúde nos anos 1980 e 1990 (na Europa Ocidental e América Latina), tinha como objetivo produzir uma mudança no papel e grau de intervenção do Estado na área social, inclusive na saúde. Duas vias de reforma foram empregadas nesse período: a primeira se refere à separação entre provisão e financiamento, com a mediação realizada por meio de contratos, e à ampliação da participação das companhias de seguro-saúde privadas na gestão da cobertura e prestação de serviços; já a segunda, diz respeito às medidas de redução da cobertura e aumento da participação privada no financiamento, incluindo a instituição de copagamentos ${ }^{8}$.

A análise comparada sugere que a expressão da crise econômica e da influência neoliberal nas reformas dos sistemas de saúde brasileiro e espanhol teve expressões variadas dada a interveniência de fatores associados ao contexto político. Na Espanha, a permanência de um partido de esquerda (Partido Socialista Espanhol - PSOE) no executivo nacional no início das reformas (1982 a 1996) e o ingresso na União Europeia (1986) destacam-se como variáveis explicativas para o avanço e a consolidação das políticas de bem-estar social e redução das desigualdades nesse período ${ }^{15}$. O ingresso na União Europeia trouxe metas de modernização econômica e aumento do gasto social, e proporcionou a entrada de recursos financeiros. Ao governo central socialista couberam ações de combate à pobreza, enquanto a responsabilidade pela assistência so- 
cial foi transferida às Comunidades Autônomas (CCAA), que entre 1989 e 1995, introduziram programas de redistribuição de renda, variados em cobertura e generosidade. O Índice de Gini na Espanha passou de 34,0 em 1980 para 31,6 em 1990, estando a estrutura e a extensão do sistema de proteção social relacionadas aos resultados de redução das desigualdades sociais ${ }^{15}$.

A partir do final dos anos 2000, sob impacto da crise econômica internacional de 2009, o sistema de saúde da Espanha sofreu outra onda de reforma, na qual se identificam pressões pela abertura do sistema público ao capital privado, por meio de medidas privatizantes e de restrição do acesso (imposição de limites ao caráter universal do sistema e instituição de copagamentos). Existem tendências variadas entre as CCAA, com maior presença de elementos restritivos na Comunidade Valenciana e menos, por exemplo, em Andaluzia ou no País Basco. Na Comunidade de Madri, recentemente, a iniciativa de privatização de hospitais públicos foi interrompida judicialmente, mediante a mobilização de trabalhadores e usuários, bem como a atuação de partidos de esquerda ${ }^{16}$.

No caso brasileiro, as limitações das políticas de bem-estar social na década de 1990 estão associadas à menor força dos partidos de esquerda no período, bem como ao ajuste macroeconômico promovido pelo executivo nacional (PRN/ PMDB, de 1990 a 1994; e PSDB, de 1995 a 1998), que restringiu a política social, promovendo resultados negativos para o desenvolvimento de longo prazo $^{15}$. Vários países latino-americanos, inclusive o Brasil, estiveram submetidos às pres- crições do Consenso de Washington (de 1989) no contexto de crise financeira dos anos 1990. As pressões impostas pelo Fundo Monetário Internacional e pelo Banco Mundial envolveram a contenção do gasto social e o incentivo a parcerias com prestadores privados no âmbito da política social ${ }^{17}$.

Nos anos 2000, a ascensão do Partido dos Trabalhadores (PT) ao executivo nacional e a retomada do crescimento econômico (sobretudo no período 2006-2008) são relacionadas à ampliação dos gastos sociais com impactos positivos sobre a redução de desigualdades. O Índice de Gini no Brasil passou de 56,0 em 1980 para 60,4 em $1990^{15}$ e caiu para $52 \mathrm{em} 2011^{18}$. Vale ressaltar a instituição do Programa Bolsa Família em 2003, constituindo-se como uma importante estratégia de combate à pobreza e diferenciando-se dos programas de redistribuição de renda anteriores por promover a articulação intersetorial, intergovernamental e entre governo e sociedade civil ${ }^{19}$.

O Gráfico 1 mostra a evolução do gasto social público, como percentual do PIB, no Brasil e na Espanha, entre 1990 e 2009. No Brasil, identificase uma trajetória de oscilações nos anos 1990 e de maior estabilidade nos anos 2000. Na Espanha, nota-se uma trajetória ascendente de 1990 a 1993 , quando começa a decair até atingir $19,8 \%$ do PIB em 2001, retomando o crescimento até 2009 (quando atinge o maior percentual dos últimos 20 anos, o que também ocorre no Brasil). Em 2009, o PIB brasileiro e o espanhol registraram variação negativa ${ }^{20}$, o que pode ter influenciado esse indicador. Comparativamente, o gasto social público,

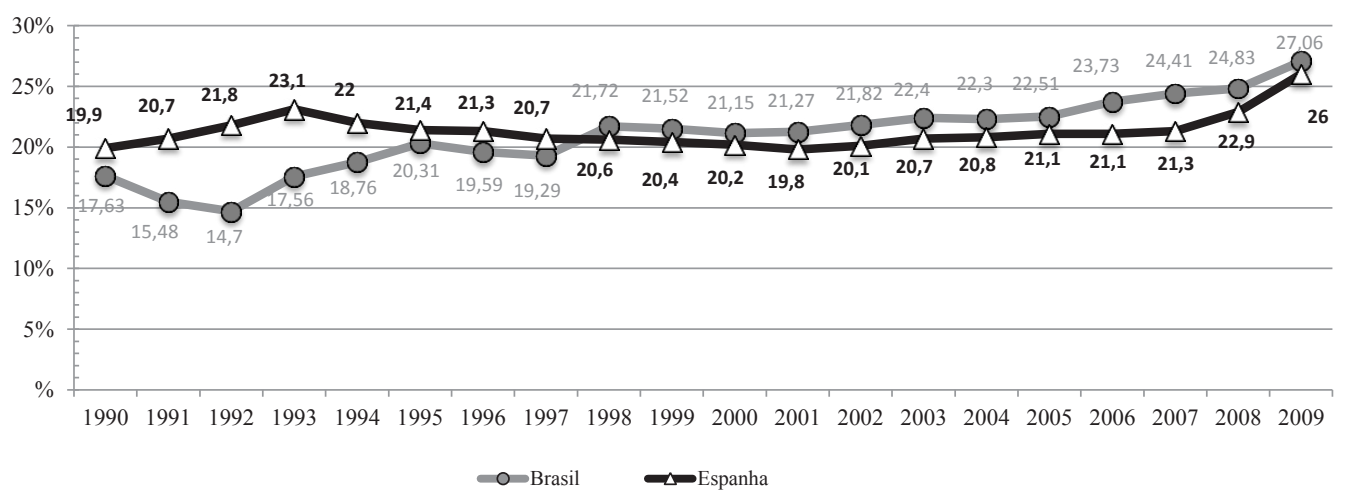

Gráfico 1. Gasto social público total (\% do PIB). Brasil e Espanha. 1990 a 2009.

Fonte: Elaboração própria a partir de Comisión Económica para América Latina y el Caribe (CEPAL ${ }^{21}$. Obs.: Dados da Espanha: OCDE/Base de dados de gasto social via $\mathrm{CEPAL}^{21}$. 
como percentual do PIB, manteve-se próximo nos dois países a partir de 1998, com o indicador para o Brasil ligeiramente acima do espanhol.

\section{Trajetória e institucionalidade da descentralização e da regionalização da saúde}

A institucionalidade da descentralização e da regionalização da saúde caracteriza-se pelos sentidos e objetivos expressos formalmente na política de saúde no contexto de redemocratização do Estado e reforma sanitária. Tal institucionalidade guarda relação com a trajetória desses processos em cada caso, assim como com as características da descentralização mais geral dos Estados brasileiro e espanhol (contexto estatal).

No Brasil, a descentralização da saúde se constitui como um processo de transferência de poder político, administrativo e financeiro aos governos subnacionais, com responsabilidade compartilhada entre as esferas gestoras. Isso resulta de um arranjo federativo em que se destaca o peso do governo central e a interdependência entre os entes. Diferente do caso brasileiro, na Espanha, a descentralização da saúde configura um processo de devolução da competência sanitária às CCAA, com transferência de poder político, administrativo e financeiro. Esse arranjo é consequência da divisão do poder territorial na Espanha, que se caracteriza por ampla autonomia dos governos subnacionais e por pressões a favor da sua maximização, com prejuízos para as relações intergovernamentais.

Quanto à regionalização da saúde, a análise comparada revela semelhanças entre os objetivos formais nos dois casos, estando presentes metas relacionadas à integralidade da atenção, à coordenação assistencial, à aproximação dos serviços aos usuários e à gestão descentralizada e participativa. No Brasil, a regionalização possui um sentido associado à organização de redes assistenciais e sua hierarquização no território, contudo, as concepções atreladas a este processo variaram ao longo da implementação do SUS ${ }^{22}$. No caso espanhol, a regionalização é compreendida como a organização territorial dos serviços de saúde, estabelecida a partir de recortes regionais definidos no marco legal do sistema e mantidos como sua base organizativa, ainda que tenham sofrido adaptações ao longo do tempo e entre as CCAA. A Lei Geral da Saúde ${ }^{23}$ propôs um desenho de áreas e zonas de saúde, influenciada pelas diretrizes da Reforma da Atenção Primária à Saúde publicadas em 1984 por meio do Real Decreto 137.
De acordo com a Lei Geral da Saúde ${ }^{23}$, as zonas de saúde constituem o marco territorial da atenção primária; e as áreas de saúde correspondem aos espaços responsáveis por garantir a integralidade da atenção (primária e especializada).

A trajetória da descentralização e da regionalização da política de saúde no Brasil se caracteriza por um processo gradual, com início anterior à implementação do SUS e transferência progressiva de responsabilidades e recursos do nível federal para os níveis municipal e estadual, regulada nacionalmente. A descentralização para os municípios foi fortemente induzida ao longo dos anos 1990, gerando aumento da capacidade institucional nessa esfera para a gestão do SUS.

A regionalização teve pouca expressão nas normas que regularam a descentralização na década de 1990, e, somente a partir dos anos 2000, recebeu ênfase no plano nacional. Isso se relaciona a sua trajetória, marcada pela tensão com a descentralização municipalista nos anos 1990 e o destaque ao papel dos estados na gestão do SUS desde 2000. Em 2011, a regionalização foi associada à formalização contratual das regiões e das responsabilidades dos gestores das três esferas de governo por meio do Contrato Organizativo da Ação Pública (COAP) previsto no Decreto 7.508/2011. Foram instituídas as Comissões Intergestores Regionais (CIR) (em substituição aos Colegiados de Gestão Regional - CGR, propostos em 2006), evidenciando um sentido político ao processo (e não apenas organizacional, como é característico do caso espanhol).

$\mathrm{Na}$ Espanha, a trajetória da descentralização e da regionalização da política de saúde foi marcada por um processo paulatino e assimétrico, resultando na conformação de 17 Serviços Regionais de Saúde (um em cada CCAA). Houve ruptura de um modelo centralizado (INSALUD) para o descentralizado (SNS), no qual as CCAA possuem amplo poder para formular, planejar e regular a política de saúde em seus territórios, bem como para gerir a rede de serviços, equipamentos e trabalhadores. Ainda que não tenham amplo poder fiscal, as CCAA possuem competências para gerir os recursos da saúde que não são condicionados a finalidades específicas de gasto. Diferente do caso brasileiro, a regionalização dos serviços de saúde é um traço de continuidade na organização do SNS, que se expressa em sua configuração atual.

No Brasil, também ocorreu a ruptura de um modelo centralizado (Inamps) para o descentralizado (SUS), contudo, diferente do caso espanhol, o nível central manteve-se como um ator 
importante na coordenação da política de saúde, ainda que estados e municípios tenham ampliado sua autonomia relativa. Esse traço de continuidade segue presente na configuração atual do SUS.

\section{Condicionantes da descentralização e da regionalização da saúde}

Os condicionantes dos processos de descentralização e regionalização da saúde, no Brasil e na Espanha, guardam relação direta com o contexto mais geral de descentralização do Estado posterior à redemocratização (contexto estatal), bem como com a trajetória e institucionalidade da descentralização e regionalização da saúde.

$\mathrm{Na}$ Espanha, regionalismos e tendências separatistas, no bojo da redemocratização, condicionaram a descentralização do Estado, resultando na constituição das CCAA. A descentralização de grande parte dos serviços sociais para as CCAA, incluindo a saúde, influenciou o aumento do gasto social e sanitário na Espanha, já que ao assumirem a gestão dos mesmos, as CCAA pressionavam o governo central por mais recursos. Além disso, dois fatores político-institucionais são estruturantes do processo de descentralização da saúde espanhol e suas repercussões sobre a configuração atual do sistema: um aumento gradual da infraestrutura de serviços públicos de saúde (expansão da cobertura territorial, embora variável entre as regiões); e da população coberta ainda no âmbito do Seguro Social, de maneira que, em 1975, a cobertura populacional era de $81 \%{ }^{24}$.

No Brasil, a redistribuição do poder territorial e a ampliação da autonomia dos entes subnacionais, com protagonismo do municipalismo, ainda que tenha sido reservado um papel de coordenação importante para a União, condicionou a descentralização da saúde. A trajetória da regionalização foi influenciada pela participação limitada dos estados na gestão da saúde nos anos 1990, bem como pela recuperação da sua capacidade financeira e institucional na primeira década dos anos 2000. Agrega-se ainda, o variado perfil populacional dos municípios e estados do país, que impõe limites institucionais e financeiros para que assumam suas atribuições. Além disso, três fatores político-institucionais configuram-se como condicionantes estruturais no caso brasileiro: os antecedentes do sistema universal, marcados pela presença importante dos prestadores privados; grandes diferenças em termos de distribuição dos serviços públicos no território; e baixa cobertura populacional na vigência do Seguro Social.

No Brasil e na Espanha, o início dos processos de reforma dos sistemas de saúde foi marcado por restrições financeiras impostas pela conjuntura econômica e pelas pressões da retórica neoliberal. Na Espanha, a crise dos anos 1980 (iniciada no final dos 1970) e, no Brasil, a crise da década de 1990 tiveram repercussões variadas sobre a gestão e o financiamento da saúde, dada a influência do contexto político em cada caso, como já apresentado.

O Gráfico 2 apresenta a evolução do gasto em saúde, como percentual do PIB, entre 1995 e 2011, no Brasil e na Espanha, destacando a relação entre o gasto total e o gasto público em saúde. Nota-se que a Espanha manteve um patamar de gasto total, como percentual do PIB, que superou o brasileiro em parte do período, ainda que esses patamares tenham se aproximado entre os anos 2000 a 2002 e 2005 a 2007. Contudo, enquanto no Brasil a proporção do gasto público em saúde sobre o gasto total foi inferior a $50 \%$ em todo o período; na Espanha, foi superior a 70\%. No Brasil, o gasto privado em saúde, como percentual do PIB, manteve-se acima do público, enquanto na Espanha evidencia-se o contrário.

Além dos fatores políticos, institucionais e econômicos, cabe destacar que o papel e as estratégias de atuação das instituições e dos atores envolvidos na formulação e implementação da descentralização e da regionalização da saúde também atuam como condicionantes desses processos. As instituições podem ser compreendidas como o conjunto de regras formais e informais que estrutura a relação entre os atores e os rumos das políticas, ao mesmo tempo que recebe influência deles, por meio da sua atuação política e das estratégias que estabelecem na defesa de suas ideias.

No Brasil, ressaltam-se como instituições e atores relevantes, os órgãos gestores (Ministério da Saúde, Secretarias Estaduais e Municipais) e seus conselhos representativos (CONASS, CONASEMS e COSEMS). De maneira geral, podese afirmar que os governos central e estaduais buscaram transferir para os municípios funções de prestação e gestão; e os governos estaduais e municipais buscaram ampliar sua autonomia (no que tange ao planejamento, formulação, financiamento e regulação), com apoio dos seus órgãos de representação. Tais órgãos de representação atuaram junto aos fóruns de negociação interterritorial (Comissões Intergestores Tripartite, Bipartite e Regionais - CIT, CIB e CIR), posicionando-se a favor dos interesses subnacionais. 




Gráfico 2. Gasto total e público em saúde (\% do PIB). Brasil e Espanha. 1995 a 2011.

Fonte: Elaboração própria a partir de World Health Organization (WHO $)^{25}$.

Assumindo o papel de coordenador nacional da política, com importantes funções na formulação, regulação e financiamento, a atuação do Ministério da Saúde foi marcada pelo uso de incentivos financeiros e do seu poder de normatização, influenciando os rumos da descentralização e da regionalização. O nível estadual, a partir dos anos 2000, assumiu um papel importante na condução do processo de regionalização, no financiamento e na regulação do sistema em seu território, contudo, há diversas experiências no Brasil. Em alguns casos, a atuação dos gestores estaduais favoreceu, em graus variáveis, o avanço da regionalização, dependendo de fatores históricos, estruturais ou político-institucionais presentes em cada contexto ${ }^{26}$. Os municípios possuem a responsabilidade pela gestão do sistema de saúde (no que se refere às unidades próprias e contratos com o setor privado), incluindo funções no financiamento e regulação no seu âmbito. A atuação desse ente também repercutiu sobre a descentralização e a regionalização da saúde, com destaque para sua participação na definição das diretrizes desses processos na década de 1990. Assim como no caso dos estados, o Brasil possui municípios de perfis populacionais e capacidades institucionais muito distintas, o que influencia sua atuação.

$\mathrm{Na}$ Espanha, além dos órgãos gestores (Ministério da Saúde e Conselhos Regionais de Saúde de cada CCAA), é importante a influência dos partidos políticos - em particular, a atuação do PSOE, que, estando no executivo nacional, conduziu a reforma sanitária do início dos anos 1980 a meados da década de 1990; e do Tribunal
Constitucional, que possui o papel de moderador e cuja atuação colaborou para a conquista de maior autonomia pelas CCAA nos primeiros anos da descentralização. As CCAA, com amplas competências na formulação, gestão, prestação e regulação da política e poder decisório sobre seu orçamento, atuaram para ampliar sua autonomia, tensionando o processo de descentralização e as relações intergovernamentais. Ao Ministério da Saúde espanhol couberam responsabilidades pela saúde exterior e pela política de medicamentos, além da coordenação nacional da política, papel esse que possui limitações para executar, dadas as características da descentralização do Estado e da saúde.

As dificuldades de coordenação nacional da política sanitária na Espanha se expressam no Conselho Interterritorial, fórum no qual estão representados o Ministério da Saúde e os gestores regionais das CCAA. Tal Conselho é palco frequente de disputas político-partidárias e das tensões presentes nas relações intergovernamentais na Espanha ${ }^{27}$, em função da lógica de maximização da autonomia defendida pelas CCAA. Pensado como principal instrumento de integração do SNS, vê-se limitado para se efetivar como tal. Possui um funcionamento regular de quatro reuniões anuais, ao menos, fato que o distingue dos fóruns dessa natureza estabelecidos no Brasil.

No Brasil, CIT, CIB e CIR foram constituídas no âmbito da política de saúde para favorecer a articulação intergovernamental na gestão do SUS nos âmbitos nacional, estadual e regional. Visam promover a negociação e gestão compartilhada, sendo compostas por representantes das esferas 


\section{Conclusões}

A análise histórico-comparada da descentralização e regionalização da política de saúde no Brasil e na Espanha permitiu identificar alguns fatores que condicionam tais processos: a divisão político-territoral e as características da descentralização do Estado; a estrutura de desigualdades territoriais e sociais; os processos de democratização e reforma do Estado; as conjunturas econômicas e políticas do período; os antecedentes do sistema de saúde (infraestrutura pública e cobertura populacional prévias à reforma sanitária); as características da trajetória da descentralização e da regionalização da saúde; as condições e o modelo de financiamento da política de saúde; o papel e as estratégias das instituições e atores. Observouse ainda que, em cada contexto específico, tais fatores favoreceram ou limitaram os processos estudados, sugerindo que o modo como se interrelacionaram no tempo importa para o resultado promovido.

No Brasil, a associação desses fatores não favoreceu que a regionalização fosse articulada à descentralização da saúde. Já na Espanha, a interface entre alguns fatores (a expansão da infraestrutura pública de serviços e da cobertura populacional antes da instituição do SNS; a atuação do PSOE nos primeiros anos da reforma sanitária e o ingresso da Espanha na União Europeia; e a estrutura do financiamento do setor, na qual predomina o gasto público) favoreceu a descentralização e a regionalização da saúde.

O resultado dessas associações exerce influência sobre a configuração recente desses sistemas de saúde, incidindo diretamente sobre quatro aspectos: organização territorial dos serviços; balanço de poder entre as esferas governamentais na gestão do sistema; ator que detém maior responsabilidade na coordenação da política; características e repartição de responsabilidades sobre o financiamento do setor.

No Brasil, a configuração atual do SUS está marcada por uma organização de base municipal, por meio da qual são construídas redes de atenção, em alguns casos articuladas a regiões de

saúde definidas a partir de um planejamento regional que considera as necessidades de saúde da população e a capacidade de oferta de serviços. O modelo federativo condiciona o modelo institucional do SUS, apontando para uma configuração pautada na gestão compartilhada. Nesse sentido, cabe destacar que, se por um lado, o balanço de poder consequente ao arranjo federativo indica menor autonomia dos governos subnacionais; por outro, tal arranjo favorece a coordenação intergovernamental, dimensão importante para a gestão da política de saúde em uma realidade tão diversa quanto à brasileira. Além disso, ainda que as três esferas de governo estejam definidas como autoridades sanitárias no SUS, o Ministério da Saúde se configura como o ator que detém um papel central na coordenação da política, com capacidade de influenciar a decisão dos seus rumos no âmbito subnacional. Na configuração recente do SUS, o financiamento é tripartite, contudo, o maior desafio está na sua estabilidade, visto que o gasto privado já supera o gasto público (como \% do PIB) e que há perspectivas de que o orçamento federal da saúde seja reduzido nos próximos anos.

Na Espanha, a configuração atual do SNS se caracteriza pela organização regional dos serviços de saúde, base que estrutura o funcionamento do sistema historicamente. O balanço de poder revela que os níveis regionais (CCAA) possuem maior autonomia na gestão do sistema, de maneira que as CCAA configuram-se como os atores que detêm maior responsabilidade pela coordenação da política e do sistema nos seus territórios. Na configuração recente, a arrecadação fiscal está centralizada no governo central, que redistribui os recursos para as CCAA em um processo que valoriza a equidade e a unidade do sistema. Algumas CCAA têm questionado essas regras e essa questão, caso sofra alterações, pode trazer consequências para a configuração e resultados do sistema.

Um balanço final aponta desafios atuais do SUS inerentes à coordenação federativa, ao financiamento público e à regionalização da saúde, que apesar dos avanços da última década, não se consolidou como base organizativa do SUS, com consequências para a equidade no acesso e integralidade da atenção. $\mathrm{O}$ fortalecimento da gestão compartilhada no âmbito regional, por meio do CIR, pode favorecer conquistas nesse sentido.

Entre os desafios atuais do SNS espanhol está o estabelecimento de relações articuladas entre esferas de governo (no âmbito do Conselho Interterritorial) e de coordenação nacional da 
Quadro 2. Análise histórica, institucional e política da descentralização e regionalização na política de saúde brasileira e espanhola.

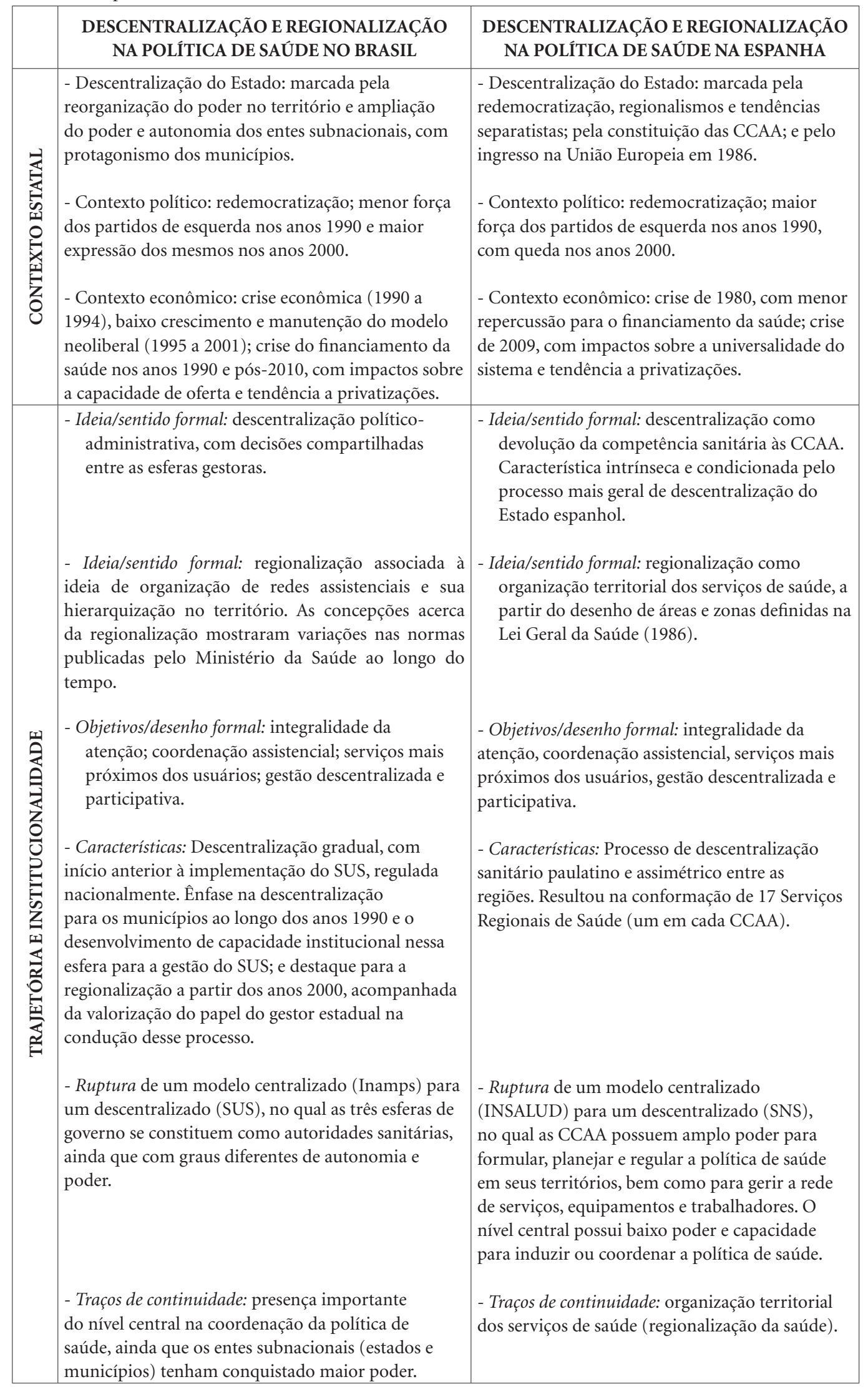


Quadro 2. Análise histórica, institucional e política da descentralização e regionalização na política de saúde brasileira e espanhola.

\begin{tabular}{|c|c|c|}
\hline & $\begin{array}{l}\text { DESCENTRALIZAÇÃO E REGIONALIZAÇÃO } \\
\text { NA POLÍTICA DE SAÚDE NO BRASIL }\end{array}$ & $\begin{array}{l}\text { DESCENTRALIZAÇÃO E REGIONALIZAÇÃO } \\
\text { NA POLÍTICA DE SAÚDE NA ESPANHA }\end{array}$ \\
\hline & $\begin{array}{l}\text { - Fatores politicos, institucionais e econômicos: baixa } \\
\text { cobertura do sistema de proteção social antes da } \\
\text { criação do SUS, com distribuição irregular dos } \\
\text { serviços de saúde no território; historicamente, } \\
\text { composição do gasto em saúde com grande peso da } \\
\text { participação do gasto privado. } \\
\text { - Instituições e atores envolvidos no processo de } \\
\text { formulação e implementação: Ministério da Saúde; } \\
\text { Secretarias Estaduais de Saúde (SES) e Conselho } \\
\text { Nacional de Secretários Estaduais de Saúde } \\
\text { (CONASS); Secretarias Municipais de Saúde (SMS) } \\
\text { e Conselho de Secretários Municipais de Saúde } \\
\text { (CONASEMS e COSEMS). } \\
\text { - Papel das instituições e atores: União possui o } \\
\text { papel de coordenador nacional da política e do } \\
\text { sistema de saúde, principal formulador, com atuação } \\
\text { importante na regulação e financiamento. O nível } \\
\text { estadual possui o papel de condutor do processo } \\
\text { de regionalização, com funções no financiamento } \\
\text { e regulação no seu território. O município possui } \\
\text { responsabilidade pela gestão e direção do sistema } \\
\text { de saúde no seu território (estrutura, equipamentos } \\
\text { e trabalhadores), incluindo contratos com o setor } \\
\text { privado; também é responsável pelo financiamento } \\
\text { e regulação. Os órgãos de representação dos estados } \\
\text { (CONASS) e municípios (CONASEMS e COSEMS) } \\
\text { atuam junto à CIT ou CIB, posicionando-se a favor } \\
\text { dos interesses subnacionais. } \\
\text { - Estratégias de atuação das instituições e atores: } \\
\text { governo central fez uso de incentivos financeiros e } \\
\text { da normatização; os governos central e estaduais } \\
\text { buscaram transferir para os municípios funções } \\
\text { de prestação e gestão; os governos estaduais e } \\
\text { municipais buscaram ampliar seu poder (no que } \\
\text { tange ao planejamento, formulação, financiamento } \\
\text { e regulação), com apoio dos seus órgãos de } \\
\text { representação. CIT, CIB e CIR configuram-se como } \\
\text { arenas de negociação de tais estratégias. }\end{array}$ & $\begin{array}{l}\text { - Papel das instituições e dos atores: governos } \\
\text { regionais (CCAA) possuem amplas competências } \\
\text { na formulação, gestão, prestação e regulação } \\
\text { da política de saúde, bem como amplo poder } \\
\text { para decidir sobre seu orçamento e os gastos } \\
\text { em saúde. Ao nível central cabe exercer a } \\
\text { coordenação nacional (papel difícil de executar } \\
\text { diante das características e condicionantes do } \\
\text { processo de descentralização do Estado e da } \\
\text { saúde), bem como responsabilizar-se pela saúde } \\
\text { exterior e política de medicamentos. Províncias e } \\
\text { municípios têm um papel restrito. }\end{array}$ \\
\hline
\end{tabular}

Fonte: Elaboração própria.

política, tendo em vista as preocupações com a unidade do sistema e a equidade entre as CCAA. O caso espanhol é um exemplo de que a maximização da autonomia dos governos subnacionais repercute sobre as relações intergovernamentais, em uma lógica onde maior autonomia subnacional corresponde a menor coordenação e cooperação intergovernamental.
Além disso, a análise dos casos permitiu mapear algumas tendências na gestão dos sistemas de saúde. No Brasil, notou-se uma valorização da relação legal ou contratual na conformação das regiões de saúde e na responsabilização dos gestores das três esferas de governo nesse âmbito. $\mathrm{Na}$ Espanha, foi possível perceber uma tendência à gestão do território, ou seja, à unificação da 
gestão da rede de atenção primária e da especializada/hospitalar presentes em uma dada região de saúde em uma direção única, com objetivo de promover a integração entre os níveis assistenciais com vistas à melhoria da eficiência na gestão e prestação de serviços. Uma tendência comum aos casos, e preocupante para a continuidade dos sistemas universais, refere-se aos movimentos de privatização, que se expressam de variadas formas, entre as quais as terceirizações, cessões e contratos com organizações sociais.

\section{Colaboradores}

AMM Pereira participou do levantamento do material empírico, análise dos resultados, concepção, redação e revisão final do artigo. LD Lima e CV Machado participaram da concepção, redação e revisão final do artigo.

\section{Agradecimentos}

Agradecemos a José Manuel Freire, professor da Escuela Nacional de Sanidad, Instituto de Salud Carlos III (Madrid, Espanha), por sua contribuição à discussão do caso espanhol.

Pereira AMM foi bolsista da Coordenação de Aperfeiçoamento de Pessoal de Nível Superior (Capes) por meio do Programa de Doutorado no País com Estágio no Exterior.

Lima LD e Machado CV são bolsistas de produtividade em pesquisa do Conselho Nacional de Desenvolvimento Científico e Tecnológico (CNPq). 


\section{Referências}

1. Melo MA. Crise federativa, guerra fiscal e "hobbesianismo municipal": efeitos perversos da descentralização? São Paulo em Perspectiva 1996; 10(3):11-20.

2. Saltman RB, Bankauskaite V. Conceptualizing decentralization in European health systems: a functional perspective. Health Economics, Policy and Law 2006; 1(2):127-147.

3. Abrucio FL. Para além da descentralização: os desafios da coordenação federativa no Brasil. In: Fleury S, organizador. Democracia, descentralização e desenvolvimento: Brasil e Espanha. Rio de Janeiro: FGV; 2006. p. 77-125.

4. Bankauskaite V, Dubois HFW, Saltman RB. Patterns of decentralization across European health systems. In: Saltman RB, Bankauskaite V, Vrangbæk K, organizadores. Decentralization in health care: strategies and outcomes. London: Open University Press; 2007. p. 22-43.

5. García JM, Sotelo JA. España en los comienzos del siglo XXI: los contextos regionales. In: García JM, Sotelo JA, organizadores. La España de las Autonomías. Madrid: Síntesis; 1999. p. 14-28.

6. Viana ALD, Lima LD, Oliveira RG. Descentralização e federalismo: a política de saúde em novo contexto - lições do caso brasileiro. Cien Saude Colet 2002; 7(3):493-507.

7. Rocha CV. Significados e tendências do federalismo e das relações intergovernamentais no Brasil e na Espanha. In: Hochman G, Faria CAP, organizadores. Federalismo e políticas públicas no Brasil. Rio de Janeiro: Fiocruz; 2013. p. 29-64.

8. Rey Del Castillo J. Arquitectura e instrumentos de cohesión en el Sistema Nacional de Salud. In: Repullo JR, Oteo LA, organizadores. Un nuevo contrato social para un sistema nacional de salud sostenible. Barcelona: Ariel; 2005. p. 267-289.

9. Lima LD, Machado CV, Baptista TWF, Pereira AMM. O pacto federativo brasileiro e o papel do gestor estadual do SUS. In: Ugá MA, Sá MC, Martins M, Braga-Neto F, organizadores. Política de saúde no estado do Rio de Janeiro. Rio de Janeiro: Fiocruz; 2010. p. 27-58.

10. Thelen K, Steinmo S. Historical institucionalism in comparative politics. In: Thelen K, Steinmo S, Longstreth F, organizadores. Structuring Politics. Historical Institucionalism in Comparative Analysis. Cambridge: Cambridge University Press; 1992. p. 1-32.

11. Immergut $\mathrm{E}$. The theoretical core of the new institutionalism. Politics and Society 1998; 26(1):5-34.

12. Mahoney J, Rueschemeyer D. Comparative Historical Analysis in the Social Sciences. Cambridge: Cambridge University Press; 2003.

13. Meny I, Thoenig JC. La dimensión comparativa de las políticas públicas. In: Meny I, Thoenig JC, organizadores. Las políticas públicas. Barcelona: Ariel Ciencia Política; 1992. p. 223-244.

14. Arretche M. Democracia, federalismo e centralização no Brasil. Rio de Janeiro: FGV, Fiocruz; 2012.
15. Huber E, Stephens JD. Iberia and the advanced Latin American Social Policy Regimes: explaining the different trajectories. In: Huber E, Stephens JD. Democracy and the Left: social policy and inequality in Latin America. Chicago: The University of Chicago Press; 2012. p. 208-239.

16. Pereira AMM, Lima LD, Machado CV, Freire JM. Descentralização e regionalização em saúde na Espanha: trajetórias, características e condicionantes. Saúde Debate 2015; 39(N. esp):11-27.

17. Mattos RA. As agências internacionais e as políticas de saúde nos anos 90: um panorama geral da oferta de ideias. Cien Saude Colet 2001; 6(2):377-389.

18. World Bank. Overview: Brazil. [acessado 2017 Out 1]. Disponível em: http://www.worldbank.org/en/country/brazil/overview

19. Santos CRB, Magalhães R. Pobreza e política social: a implementação de programas complementares do Programa Bolsa Família. Cien Saude Colet 2012; 17(5):1215-1224.

20. World Bank. Data. GDP growth (annual). [acessado 2017 Out 1]. Disponível em: http://data.worldbank. org/indicator/NY.GDP.MKTP.KD.ZG/countries/ BR-XJ-ES-EU?display=graph

21. Comisión Económica para América Latina y el Caribe. Cepalstat. [acessado 2017 Out 1]. Disponível em: http:// estadisticas.cepal.org/cepalstat/WEB_CEPALSTAT/estadisticasIndicadores.asp?idioma $=\mathrm{e}$

22. Albuquerque MV, Viana ALD. Perspectivas de região e redes na política de saúde brasileira. Saúde Debate 2015; 39(N. esp):28-38.

23. Espanha. Lei Geral da Saúde. Lei 14/1986, de 25 de abril. [acessado 2017 Set 1]. Disponível em: http:// www.diputados.gob.mx/LeyesBiblio/

24. Freire JM. La cobertura poblacional del Sistema Nacional de Salud: importancia y retos de la universalización y la equidad en el aseguramiento. In: Repullo JR, Oteo LA, organizadores. Un nuevo contrato social para un sistema nacional de salud sostenible. Barcelona: Ariel; 2005. p. 61-99.

25. World Health Organization (WHO). Global Health Observatory Data Repository. [acessado 2017 Out 1]. Disponível em: http://apps.who.int/ghodata/

26. Viana ALD, Lima LD, organizadores. Regionalização e relações federativas na política de saúde do Brasil. Rio de Janeiro: Contra Capa; 2011.

27. Freire JM. El Sistema Nacional de Salud español en perspectiva comparada europea: diferencias, similitudes, retos $y$ opciones. Madrid: ISCIII; 2008.

Artigo apresentado em 31/01/2018

Aprovado em 12/03/2018

Versão final apresentada em 03/04/2018 
